\title{
Eine Bemerkung zu der Mitteilung von Warburg und Meyerh of uber die katalytische Beschleunigung der Sauerstoffaufnahme des Lecithins durch Eisensalze.
}

\author{
Von \\ T. Thunberg.
}

(Aus dem physiologiachen Institut der Universităt zu Lund, Srhweden.) (Der Redaktion zugegangen am 17. Juli 1913.)

In Band $58,5.412$, dieser Zeitschrift komml eine vorläufige Mitteilung von Warburg und Meyerhof vor, welche die Jxydation von Lecithin bei Gegenwart von Eisensalz behandelt. Die Verfasser teilen mit, daß das als \&Lecithin bezeichnete Substanzgemisch sich bei Zimmertemperatur mit großer Geschwindigkeit an der Luft oxydiert, wenn man seiner wässerigen Suspension etwas Eisensalz zusetzt, und glauben, daß diese Tatsache von ihnen entdeckt worden ist. - Ich erlaube mir indessen zu bemerken, daß ich diese Tatsache schon vor einigen Jahren gefunden und bereits einige Mitteilungen darüber veröffentlicht habe. Siehe Thunberg, Über katalytische Beschleunigung der Sauerstoffaufnahme der Muskelsubstanz, Zentralbl. f: Phỵsiol., Bd. 23, 1909, und Thunberg, Unlersuchungen über autoxydable Substanzen und autoxỵdable Systeme von physiologischem Interesse. Erste Mitteilung, Skand. Archiv f. Physiol., Bd. 24, 1910; Zweite Nitteilung, ibid.

Da der Vortrag Warburgs eÜber die Wirkung der Struktur auf chemische Vorgänge in Zellen» (Jena, Gustav Fischer, 1913! anzuzeigen scheint, daß er auch meine Arbeiten auf diesem Gebiete nicht kennt, erlaube ich mir, diese Gelegenheit zu henutzen, um die Aufmerksamkeit auf meine Untersuchungen über die Beeinflussung der vitalen Oxydationserscheinungen durch rorhergehendes Frieren und durch Zerreiben der Zellen zu lenken. Siehe die Festschrift für. Ol of Hammarsten (Upsala und Wiesbaden, 1906); Thunbèrg, Mikrorespirometrische Untersuchungen über den Gasaustausch der Muskeln, und Thunberg, Studien über die Beeinflussung des Gasaustausches des überlebenden Froschmuskels durch verschiedene Stoffe, Erste Mitteilung, Skand. Archiv, Bd. 22, 1909. Wahrscheinlich bedürfen indessen die Beobachtungen, welche ich in dem Kapitel sÜber die Einwirkung eines vorhergehenden Frierens auf den Gasaustausch des herauspräparierten Muskels s in der Ha m marstenschen Festschrift veröffentlicht habe, einer Korrektion. Die Kohlensäureabgabe ist durch eine nicht berïcksichtigte Fehlerquelle etwas zu hoch erhalten worden, wie ich durch spätere Versuche gefunden habe. 